\title{
Young, male, and infected: the forgotten victims of chlamydia in primary care
}

\author{
P Robertson, O E Williams
}

See end of article for authors' affiliations

.....................

Correspondence to:

DrO E Williams,

Department of

Genitourinary Medicine,

Wrexham Maelor

Hospital, Croesnewydd

Road, Wrexham LL13

TTD, UK; olwen.williams@

new-tr.wales.nhs.uk

Accepted for publication 17 July 2004
Objectives: To identify current levels of testing men for chlamydia and establish levels of knowledge relating to chlamydia infection among practice nurses in primary care in one north Wales local area health group (LHG) as part of a study to improve delivery of sexual health services in primary care.

Methods: Anonymous confidential self completed postal questionnaires were sent to 46 practice nurses employed at 22 GP practices within one north Wales LHG. On return of the questionnaires and analysis of the data using SPSS, semistructured interviews with seven practice nurses were undertaken.

Results: Responses were obtained from 33/46 (71.7\%) practice nurses. The majority, 30 (90.9\%), do not examine male genitalia and 18 (54.5\%) have never tested male patients for chlamydia infection. 28 (84.8\%) practice nurses do not consider contact tracing as part of their role.

Conclusions: Primary care has a pivotal part to play in reducing prevalence of chlamydia. The paucity of male testing for chlamydia and a lack of consistent uniform testing and contact tracing in primary care has implications for the prevalence and long term consequences of infection. There is scope to greatly increase male testing for chlamydia both for those presenting with signs and symptoms of infection and those asymptomatic. This cannot be achieved without both educational and financial support for practice nurses.
G enital Chlamydia trachomatis remains year on year the most common sexually transmitted infection in the United Kingdom. ${ }^{1}$ In 1998 the chief medical officer's expert advisory panel on chlamydia published its report, which concluded that testing should be offered to sexually active women under 25 years of age and to those over 25 years with two or more sexual partners within 12 months. The report also emphasised the importance of general practice in contact tracing and the need for collaboration between genitourinary medicine (GUM) and primary care. The report did not, however, make explicit the need for male screening or how detection of infected males needs to be addressed by primary care. ${ }^{2}$

While it is recognised that females often disproportionately bear the main burden of morbidity from chlamydial infection, it is often overlooked that chlamydia puts a heavy burden on male health causing epididymitis and infertility. ${ }^{3}$ The highest infection rates are currently documented in young women between 16-24 years of age, but as male testing is not pursued with the vigour of female testing are we really sure of infection levels in young males?

Although healthcare professionals' awareness of chlamydia is rising, GUM clinics remain the only clinical setting that routinely test for chlamydia, yet it is estimated that only $10 \%$ of prevalent infection is diagnosed in GUM clinics. ${ }^{4}$ There remains a lack of availability of nucleic acid amplification tests (NAATs) and data on chlamydia testing practices and detection rates within primary care. ${ }^{5}$

In view of this, improvement in detection, treatment, and management including contact tracing within sexual health services in primary care is desirable. This study was conducted following the piloting of a care pathway for chlamydia and the availability of a urine strand displacement assay (SDA, Beckton Dickinson, USA) in the 6 months before the research.

\section{OBJECTIVES}

To identify current levels of male testing and establish levels of knowledge relating to chlamydial infection among practice nurses in primary care in one north Wales local area health group (LHG) as part of a study to improve delivery of sexual health services in primary care.

\section{METHOD}

\section{Study design}

The questionnaire was designed to establish current levels of male testing and identify knowledge levels of chlamydial infection among practice nurses in primary care; it also aimed to elicit current practice including diagnostic tests being taken for male testing and indications prompting testing. The questionnaire was developed to suit the study and a draft questionnaire was piloted on four health professionals and amended according to feedback obtained.

Data from the questionnaire were summarised using frequency counts and percentages. When presenting the key results, it is important to show the effect that the relatively small sample size of this study may have had on these values. Therefore, 95\% confidence intervals have been calculated for the key results.

Semistructured interviews were then undertaken with practice nurses who agreed to be interviewed with the aim of gaining further insight into the beliefs and knowledge base of the practice nurses.

Ethical approval was granted from North East Wales ethics committee (west, central, and east subcommittees). A research and development grant for costs to undertake the study was awarded by North East Wales NHS Trust.

\section{Data collection}

Data for the study were collected using a structured anonymous confidential self completed postal questionnaire. For the purpose of the study, 46 individually addressed questionnaires were sent to all the practice nurses employed at 22 GP practices. Reminder letters were sent out 1 week later and reminder telephone calls made to all nonresponders 1 week later. The questionnaires were anonymous

Abbreviations: GUM, genitourinary medicine; LHG, local area health group; NAATs, nucleic acid amplification tests; SDA, strand displacement assay 
and confidential, but a request was included in each letter for nurses who would be willing to take part in semistructured interviews as the second part of the study to provide their names and practice contact details. Data from returned questionnaires were analysed using the SPSS statistical package to establish concurring themes.

\section{RESULTS}

There was a $71.7 \%$ (33/46) response rate, with all 22 GP practices being represented. Seven nurses took part in semistructured interviews.

\section{Responses to questionnaires}

Examination of male genitalia was not carried out routinely by $30 / 33$ (90.9\%, 95\% CI 76.4 to 96.9$)$ practice nurses. Of the 18 nurses who responded to the question all indicated they were not performing urethral swabs for chlamydia on men. Urine SDA for detection of chlamydia had been used by $15 / 33$ $(45.5 \%, 95 \%$ CI 29.8 to 62.0$)$ nurses.

In response to the question on when respondents would initiate chlamydia testing on a male patient, the five scenarios elicited consistent responses by one practice nurse $1 / 33$ (3.0\% 95\% CI 0.5 to 15.3 ) who always initiated testing (table 1). No responses were obtained from approximately $60 \%$ of nurses. The indication that prompted most individuals to initiate chlamydia testing was that the patient's partner had chlamydia, $11 / 33$ (33.3\%). Eleven out of 33 (33.3\%) nurses stated that a male GP carried out chlamydia testing in their practice.

Referral of male patients with chlamydia to a GUM clinic was the routine practice of 20/33 (60.6\%) nurses. Method of referral varied, 10/33 (30.3\%) gave verbal advice only, while $23 / 33(69.7 \%)$ nurses used two or more methods of referral including verbal, letter, and/or arranged clinic appointment by telephone on the patient's behalf (table 1).

Contact tracing was not seen as part of the practice nurse's role in delivering sexual health care by $28(84.8 \%)$ practice nurses, three $(9.1 \%)$ saw it as part of their role and two $(6.1 \%)$ left the question blank. A number of nurses commented in the free text that they thought they did not have the time to become involved in contact tracing (box l).

Respondents were asked what advice they give to a patient who has tested positive for chlamydia about recent sexual contacts, of which 29/33 (87.9\%) nurses stated they advised that recent sexual contacts should be tested/treated. Twenty nine nurses do not offer to see sexual contacts even if they are from the same GP practice as the positive patients, four nurses do offer to see the contact. Patients were advised by $25 / 33$ (75.8\%) nurses to tell recent sexual contacts to attend a GUM clinic, but $14 / 33(42.4 \%)$ would also advise contacts to see their GP.
Box 1: Selected responses to question: how do you feel about contact tracing as part of the practice nurse role in defecting and treating chlamydia?

- I would definitely need training, but we encourage patients to go to the GUM clinic, as it's a time issue and the GUM clinic can do all screens for patient. We encourage them to tell their partners. A GUM clinic still has a stigma, can they (patient) get in and out without being seen

- Wouldn't like it, haven't got time to do it as haven't got the time to do what we're supposed to. If funded to do I would (for the time)

- Very important, but wouldn't feel happy to do it as not trained to do it. Time is a factor, in an ideal world yes but time is an issue

- Cannot imagine doing it I'm afraid. Time constraints would make it very difficult. I prefer to send them to the GUM clinic, but it still has a stigma

\section{Semistructured interviews}

Seven face to face interviews were carried out; none of the interviewees had ever taken a male urethral swab, but all were prepared to undertake the task if trained. Comments made suggested lack of confidence and knowledge on how to do endourethral swabs was a significant factor in this (box 2).

The SDA chlamydia urine test had been used by $4 / 7$ respondents, while all (100\%) felt they would use the urine test if training was received on its use and four of seven felt it would be acceptable to men. All nurses stated that time was the main single factor that prevented them from partner notification. Training was highlighted specifically by two nurses and funding by one nurse to be an issue.

\section{DISCUSSION}

This study confirmed that there is a paucity of male chlamydia testing by practice nurses in primary care either opportunistic or on symptomatic males. Thirty (90.9\%) practice nurses stated they do not examine male genitalia and $18(54.5 \%)$ stated they never test males for chlamydia. These results mirror that of another study, which found that $67.5 \%$ of practice nurses never test males for chlamydia. ${ }^{6}$

Failure by nurses to identify the signs and symptoms of chlamydia in males represents lost opportunities to test and has implications for risk of complications developing and the

Table 1 Responses to questionnaire

\begin{tabular}{|c|c|c|c|c|}
\hline $\begin{array}{l}\text { In which of the following circumstances would you test male patients } \\
\text { for genital chlamydia infection? }\end{array}$ & Always & Sometimes & Never & No response \\
\hline Aged under 25 & $1(3.0 \%)$ & $5(15.2 \%)$ & $6(18.2 \%)$ & $21(63.6 \%)$ \\
\hline Who complains of dysuria tingling on urination & $4(12.1 \%)$ & $6(18.2 \%)$ & $3(9.1 \%)$ & $20(60.6 \%)$ \\
\hline Who complains of painful testicles & $4(12.1 \%)$ & $3(9.1 \%)$ & $5(15.2 \%)$ & $21(63.6 \%)$ \\
\hline Who mentions he is in a new relationship & $1(3.0 \%)$ & $7(21.2 \%)$ & $5(15.2 \%)$ & $20(60.6 \%)$ \\
\hline Partner has chlamydia & $11(33.3 \%)$ & $1(3.0 \%)$ & $3(9.1 \%)$ & $18(54.5 \%)$ \\
\hline I never test males for genital chlamydia infection & NA & NA & $18(54.5 \%)$ & $15(45.5 \%)$ \\
\hline In your work as a practice nurse do you examine male genitalia? & $\begin{array}{l}\text { Yes } \\
1(3.0 \%)\end{array}$ & $\begin{array}{l}\text { No } \\
30(90.9 \%)\end{array}$ & $\begin{array}{l}\text { No response } \\
2(6.1 \%)\end{array}$ & \\
\hline \multirow{2}{*}{$\begin{array}{l}\text { When a male patient has been diagnosed with chlamydia infection } \\
\text { do your routinely refer him to the GUM clinic? }\end{array}$} & Yes & No & No response & \\
\hline & $20(60 \%)$ & $7(21.2 \%)$ & $6(18.2 \%)$ & \\
\hline \multirow{2}{*}{$\begin{array}{l}\text { When a patient is diagnosed with chlamydia infection do you } \\
\text { consider partner notification (contact tracing) to be part of your } \\
\text { role as a practice nurse? }\end{array}$} & Yes & No & No response & \\
\hline & $3(9.1 \%)$ & $28(84.8 \%)$ & $2(6.1 \%)$ & \\
\hline
\end{tabular}


Box 2: Semistructured interviews: how do you feel about testing men for chlamydia?

- Wouldn't bother me, but would like structured tuition to observe being done before testing one

- Never done it, never seen the male swab-will order some.

- I would definitely need training

- Wouldn't mind but never arises-more likely to go to doctors if men have problems

- Not a problem, but never taken a swab from a man. What are the training implications?

- Don't mind, but would need training

- Do not come across at all, don't know anything about it

potential increase in prevalence of infection the longer the infection remains undetected. Their lack of confidence and knowledge on how to do endourethral swabs compounds this issue. It is recommended that primary care should test anyone who presents with signs and symptoms of infection. ${ }^{7}$ Testing in low prevalence populations is cost effective and can lead to $50 \%$ reduction of long term morbidity. ${ }^{3}$

The availability of a urine test is thought to be a way to increase male testing by practice nurses as it offers a noninvasive method of opportunistic testing for infection. Results from the study indicate that those who used the urine test did test males where they had not done so before and all nurses interviewed stated they would test males if the urine test were to be available. Although this would have resource/ financial implications initially it is felt this could be offset by savings made from treatment costs having to be provided to treat long term morbidity of infection in females, as using a urine test to screen for chlamydia is cost effective ${ }^{8}$ and acceptable to the population. ${ }^{9}$ A cost-benefit analysis of screening men for chlamydia using urine testing could provide evidence, which is currently lacking on the effectiveness of testing males in primary care. ${ }^{2}$ Results from the two government pilot screening sites have established that opportunistic screening is acceptable to the population with over $70 \%$ of people offered testing taking it up and that screening can reach those most at risk in primary care. Yet it would appear from our study that a major barrier to chlamydia testing is the knowledge and skills of healthcare professionals and not population non-acceptance of testing.

Research indicates most male partners of females with chlamydia or pelvic inflammatory disease are asymptomatic, untested, and untreated and thus go on to re-infect their female partner, ${ }^{10}$ which has both economic and health consequences, a situation that is further exacerbated by no robust form of contact tracing being undertaken in primary care. ${ }^{11}$ Results of this study have highlighted that $28(84.8 \%)$ nurses do not consider contact tracing to be part of their role in sexual health provision. The figures are considerably

\section{Key messages}

- Increased scope for male testing for chlamydia in primary care

- Availability of chlamydia urine test should be increased

- Partner notification is not seen as practice nurse role

- Significant investment is required for training and educating practice nurses in the field of sexual health higher when compared to those found in other studies, ${ }^{6}$ where $54.2 \%$ of practice nurses stated they believed contact tracing was not part of their role. Comments indicate that apart from lack of time to undertake contact tracing, lack of knowledge and training how to approach the issue was a barrier to carrying it out. Contact tracing for many in primary care is a daunting prospect, as partners may not be registered with the practice and to broach such a subject with a patient can be embarrassing for both health professional and patient ${ }^{7}$; however it is economically effective. ${ }^{12}$

The study demonstrates that practice nurses are only verbally advising an individual to attend a GUM clinic. These findings concur with a recent study of patients attending a GUM clinic that found $40.5 \% \quad(39.9 \%$ had a sexually transmitted infection) of the patients seen had already been seen in primary care for their problem. ${ }^{13}$ It was found that duration of symptoms for those initially seeking treatment in primary care was substantially longer than for patients who attended GUM clinics directly. Facilitation of referral may be addressed by establishing care pathways.

This study, while small, demonstrates the urgent need to support practice nurses to carry out male testing in primary care. Currently, different levels of service and patient care for chlamydia are being provided to male patients within primary care.

Practice nurses require sexual health education and support in providing enhanced sexual health services. Development of care pathways, local training courses, and introduction of NAAT urine tests are recommended to improve the situation, and provide male patients with equity of care afforded to female patients. It is recognised that change is not spontaneous, but change is required within primary care in the form of the application of evidence based medicine/care to promote best practice and clinical effectiveness.

\section{CONTRIBUTORS}

PR carried out the data collection and analysis; PR and OW designed the questionnaire and documented the study.

\section{Authors' affiliations}

P Robertson, O E Williams, Department of Genitourinary Medicine,

Wrexham Maelor Hospital, Wrexham, UK

\section{REFERENCES}

1 Health Protection Agency, SCIEH, ISD, National Public Health Service for Wales, CDSC Northern Ireland, and UASSG. Renewing the focus. HIV and other sexually transmitted infections in the United Kingdom in 2002. London: Health Protection Agency, 2003.

2 Chief Medical Officer. Main report of the CMO's expert advisory group on chlamydia trachomatis. London: Department of Health, 1998.

3 Paavanen J. Is screening for chlamydia trachomatis infection cost effective? Genitourin Med 1997:73:103-4.

4 Pimenta J, Catchpole M, Gray M, et al. Evidence based health policy report. Screening for genital chlamydial infection. BMJ 2000;321:629-31.

5 Simms I, Hurtig AK, Rogers PA, et al. Surveillance of sexually transmitted disease in primary care. Sex Transm Infect 2003;79:174-6.

6 Cassell JA, Sutcliffe L, Holden B, et al. Is primary care ready for chlamydia? Partner notification, gender issues and attitudes to collaboration with genitourinary medicine (GUM) clinics in a variety of primary care settings across England. Sex Transm Infect 2003;79(Suppl 1):A16.

7 Grun L. Perspectives from primary care. The 4th Bandolier Conference for Chlamydia. 1998. (www.jr2.ox.ac.uk/bandolier/bandopubs/bandocon4/ chlamyd.htm)

8 Mehta DS, Shahmanesh M, Zenilman JM. Spending money to save money. Sex Transm Infect 2003;79:3-4.

9 Pimenta J, Fenton KA. Recent trends in chlamydia tracomatis in the UK and the potential for national screening. Eurosurveillance $2001 ; 6: 81-4$.

10 Robinson AJ, Greenhouse P. Prevention of recurrent pelvic infection by contact tracing: a commonsense approach. Br J Obstet Gynaecol 1996;103:859-61.

11 Catchpole M. Epidemiology of genital chlamydia trachomatis infection. The 4th Bandolier Conference for Chlamydia. 1998. (www.jr2.ox.ac.uk/ bandolier/bandopubs/bandocon4/chlamyd.htm).

12 Sutton N, Bell G, Rogstad K. An evaluation of the costs and outcomes of provider referral notification for chlamydia trachomatis. Sex Transm Infect 2003;79(Suppl 1):A11.

13 Cassell JA, Brook MG, Mercer CH, et al. Treating sexually transmitted infections in primary care: a missed opportunity? Sex Transm Infect 2003;79: 134-6. 